\title{
Estrutura Arrecadatória e Desenvolvimento Socioeconômico dos Municípios Mineiros
}

\author{
Rodrigo Silva Diniz Leroy ${ }^{1}$ \\ Luiz Antônio Abrantes ${ }^{2}$ \\ Fernanda Maria de Almeida $^{3}$ \\ Marco Aurélio Marques Ferreira ${ }^{4}$ \\ Michelle Aparecida Vieira ${ }^{5}$
}

http://dx.doi.org/10.21527/2237-6453.2017.41.164-201

Recebido em: 25/8/2015

Aceito em: 7/10/2016

\section{Resumo}

A adoção do federalismo fiscal no Brasil dotou Estados e municípios de capacidade tributária parcial, uma vez que, além de participação nas receitas tributárias da União, existe a alternativa de geração de receitas próprias. Constata-se, no entanto, que a maioria dos municípios é extremamente dependente das transferências intergovernamentais, devido ao baixo esforço fiscal, o que implica em

Doutorando em Ciências Contábeis pela Universidade Federal de Uberlândia (UFU). Mestre em Administração, com ênfase em Administração Pública, e graduado em Ciências Contábeis pela Universidade Federal de Viçosa (UFV). Professor assistente da Universidade Federal de Viçosa (UFV). leroy.rodrigo@gmail.com

2 Doutor e mestre em Administração pela Universidade Federal de Lavras (UFLA). Graduado em Administração pela Universidade Federal de Viçosa (UFV). Professor associado da Universidade Federal de Viçosa (UFV). abrantes.ufv@gmail.com

3 Doutora e mestre em Economia Aplicada pela Universidade Federal de Viçosa (UFV). Graduada em Ciências Econômicas pela mesma Universidade. Professora da Universidade Federal de Viçosa (UFV). falmeida.ufv@gmail.com

4 Doutor e mestre em Economia Aplicada pela Universidade Federal de Viçosa (UFV). Graduado em Administração pela mesma Universidade. Professor associado da Universidade Federal de Viçosa (UFV). marcoufv1@gmail.com

5 Mestra em Administração, com ênfase em Administração Pública, e graduada em Ciências Contábeis pela Universidade Federal de Viçosa (UFV). michellevieiracco@gmail.com 
insuficiência de receitas para o cumprimento de suas funções e competências básicas, influenciando no desenvolvimento municipal. Neste aspecto, este artigo objetivou identificar a relação entre a composição da arrecadação tributária própria e o nível de transferências intergovernamentais com 0 desenvolvimento socioeconômico dos municípios mineiros. Para atendimento dos objetivos, foram utilizadas técnicas de Análise Exploratória de Dados, teste Anova de diferença de médias e 0 teste Qui-Quadrado. Constatou-se que os municípios de maior potencial arrecadatório apresentam melhores desempenhos médios das variáveis relacionadas ao porte populacional, desenvolvimento municipal, renda, arrecadação própria per capita e Valor Adicionado Fiscal por setor, à exceção do VAF per capita das atividades primárias. Comprovou-se também que os grupos são distintos em relação aos níveis médios de arrecadação tributária própria, exceto em relação às receitas com ISS, que não têm associação com a classificação dos municípios nos estratos de potencial arrecadatório. Constatou-se ainda que municípios com receitas próprias per capita mais elevadas têm maiores índices médios de desenvolvimento municipal. Assim, conclui-se que tanto os níveis quanto a composição da arrecadação própria influenciam o desenvolvimento dos municípios mineiros.

Palavras-chave: Estrutura arrecadatória. Potencial de arrecadação. Desenvolvimento municipal.

\title{
TAX COLLECTION STRUCTURE AND SOCIOECONOMIC DEVELOPMENT OF MINAS GERAIS' MUNICIPALITIES
}

\begin{abstract}
The adoption of fiscal federalism in Brazil, has given states and municipalities partial tax capacity, once there is the alternative of generating their own revenues in addition to the participation in the Union tax revenues. However, it is noted that most municipalities are highly dependent on intergovernmental transfers due to their low tax effort, which implies insufficient income to fulfill their basic functions and onus, influencing municipal development. Thus, this study aimed to identify the relationship between the level of intergovernmental transfers and the composition of their own tax revenue to the socioeconomic development of municipalities from Minas Gerais. To reach the proposed objectives, were used Exploratory Data Analysis techniques, Anova test and the chi-square test. It was found that the higher revenue collecting potential municipalities have a better average performance with regards to variables related to population size, municipal development, income, municipal revenues per capita and value-added tax (VAT) by sector, except for the VAT per capita of the primary activities. It was also shown that the groups are different in average levels of own tax revenues, except when related with the revenue with ISS, which is not associated with the classification of municipalities on revenue collection potential strata. Moreover, it was found that municipalities with higher income per capita themselves have higher average levels of municipal development. Accordingly, it is concluded that the levels, as much as the composition of the own municipalities' revenues, influence the development of the municipalities from Minas Gerais.
\end{abstract}

Keywords: Tax collection structure. Tax collection potential. Municipal development. 
Após a reforma constitucional de 1988, o Brasil passou por amplo processo de descentralização fiscal, quando Estados e municípios foram dotados de maior autonomia política, legislativa e financeira, com ampliação de atribuições e responsabilidades. Em relação à autonomia financeira, a atribuição de competências tributárias distintas a estes entes tornou-os relativamente independentes, considerando a arrecadação proveniente de fontes próprias.

Constitucionalmente foi assegurada a capacidade tributária parcial aos entes federativos, em especial aos municípios, uma vez que, além de participação nas receitas tributárias da União e do Estado em que se inserem, existe a alternativa de geração de receitas próprias.

A realidade, entretanto, é adversa. Constata-se na maioria dos municípios baixo esforço fiscal, o que implica a insuficiência de receitas para o cumprimento de suas funções e competências básicas. Tal fato gera dependência e consequente aumento das transferências intergovernamentais.

Para Baião (2013), em todas as Federações do mundo a arrecadação é maior no nível mais amplo e menor nos níveis locais, fato que torna necessária a transferência de recursos da instância central aos governos subnacionais. Estas transferências, além de corrigirem o desequilíbrio vertical na Federação, ou seja, as diferenças entre atribuições e receitas nos diferentes níveis de governo, representam uma oportunidade de atenuar as disparidades regionais, uma vez que o território de uma nação raramente é homogêneo do ponto de vista econômico e social.

Além das transferências intergovernamentais, os municípios detêm a competência para instituir tributos incidentes sobre a propriedade predial e territorial urbana (IPTU), a transmissão inter vivos de bens imóveis (ITBI) e sobre a prestação de serviços de qualquer natureza (ISS), além das taxas e contribuições de sua responsabilidade (BRASIL, 1988). 
De acordo com dados da Secretaria do Tesouro Nacional (STN), no entanto, a participação aproximada dos Estados e municípios na receita disponível federal passou de 36\% no ano de 1987 para 48\% em 2012 (SECRETARIA..., 2014). Com vistas ao atendimento das necessidades básicas da população, melhorias na sua qualidade de vida e infraestrutura, este aumento de participação pode ser justificado pelas políticas de transferência e por novos meios de arrecadação de recursos destinados a financiar políticas públicas.

Para o desempenho de suas atividades e realização de seus fins, os municípios precisam obter meios financeiros, mediante a exploração de seu patrimônio, pelas contribuições representadas pelos tributos municipais e pela participação nas receitas do governo estadual e da União. Tais atividades são denominadas por Silva (1995) como gestão e administração financeira, que consiste em obter, criar, gerir e despender os recursos financeiros indispensáveis àquelas necessidades.

O fortalecimento e a consolidação da capacidade de tributação dos entes federados é consequência da adoção do federalismo fiscal e de movimentos no sentido de redistribuição dos recursos públicos, almejando amenizar as disparidades regionais e promover o desenvolvimento de forma mais igualitária do país como um todo (SERRA; AFONSO, 1999).

As mudanças consequentes da descentralização fiscal configuraram-se num avanço político, uma vez que os municípios têm relações mais estreitas com a população e, devido a isso, teriam maior conhecimento de suas carências imediatas, o que possibilitaria uma atuação mais efetiva na solução das questões sociais. Na visão de Afonso (2007), o governo, por estar mais próximo do cidadão, deveria ter flexibilidade gerencial, mas com responsabilização, para priorizar as ações escolhidas pela comunidade e realizá-las com o menor custo de transação possível. 
A maior autonomia, no entanto, gerou também aumento de suas responsabilidades para com a população, quais sejam: legislar a respeito das questões de interesse local; prover serviços públicos julgados como de caráter essencial; manter Educação Infantil; Ensino Fundamental; serviços de saúde, dentre outros (BRASIL, 1988).

Esse aumento das obrigações municipais provocou, por consequência, maior carga de responsabilidades relacionadas também com a gestão dos recursos, desencadeando uma fiscalização mais severa de suas ações, o que, principalmente com o advento da Lei de Responsabilidade Fiscal (BRASIL, 2000), tornou mais complexa a administração municipal, o que acarreta consideráveis dificuldades de gestão.

Tais dificuldades tiveram como escopo principal a escassez de receitas para custear as obrigações impostas para os municípios, visto que, apesar de sua autonomia tributária, eles têm sido extremamente dependentes das transferências governamentais. Em parte significativa dos municípios brasileiros, entretanto, essa alta dependência ocorre principalmente por fatores relacionados a interesses políticos. Este fato é reforçado por Gandini (2008) ao constatar que a tradição patrimonialista e clientelista faz parte da cultura brasileira. Tais fatores, conjugados ao baixo nível de accountability ${ }^{6}$ em âmbito municipal, promovem o desinteresse do gestor público em realizar o esforço fiscal para o aumento da arrecadação própria, muitas vezes vinculado a questões relacionadas à popularidade.

Esta questão é corroborada por Shikida (1998, p. 36), que aponta que "benefícios políticos auferidos também são um fator importante na questão das transferências. Alguns tipos de atividades podem gerar maiores benefícios (“maior popularidade") para os governos (...)".

\footnotetext{
6 "Compreende uma palavra do idioma inglês, ainda sem uma tradução específica, que envolve, todavia, a noção clara de responsabilidade na gestão de recursos públicos, de prestação de contas, de responsabilidade nas decisões de alocação de recursos públicos em atendimento a algumas demandas sociais em detrimento de outras" (BARACHO, 2000, p. 2).
} 
Outro fator importante relacionado à dependência por transferências se dá pela relação entre composição das receitas e qualidade dos serviços públicos, uma vez que, quando o município é extremamente dependente de transferências, o gestor público se exime da responsabilização dos serviços prestados. Por outro lado, aumentos nos níveis de arrecadação própria tendem a gerar maior cobrança pela população por serviços públicos de qualidade, atribuindo a responsabilização para o gestor local.

Os entraves relativos à gestão fiscal, portanto, tornam-se problemáticos, pois a escassez desta gestão afeta diretamente o desenvolvimento local, dada a necessidade de recursos para prestar serviços aos cidadãos, seguindo requisitos mínimos de qualidade.

Deste modo, segundo Oliveira e Biondini (2012), economias em estágios incipientes de desenvolvimento econômico tendem a contar também com bases estreitas e pouco diversificadas de tributação e, portanto, com limitada capacidade de arrecadação. Assim, a dependência por transferências compromete o nível de recursos para custear as necessidades dos municípios, o que pode impactar o seu desenvolvimento socioeconômico e, portanto, o bem-estar da população.

A solução para este entrave, contudo, pode estar relacionada com o desenvolvimento local, uma vez que, à medida que este avança, com a ampliação e diversificação das estruturas produtivas e dos níveis de renda per capita da população dos municípios, ampliam-se as bases da tributação. Assim, aumenta-se a capacidade do governo de arrecadar tributos do setor privado e, consequentemente, o fortalecimento das bases de financiamento.

Dessa forma, é possível que os municípios com menor dependência por transferências apresentem melhores indicadores de desenvolvimento. Considerando-se a dinâmica e a composição tributária na estrutura arrecadatória dos municípios de Minas Gerais, uma questão é levantada: as 
transferências intergovernamentais e o nível de arrecadação e composição das receitas tributárias próprias influenciam efetivamente o desempenho socioeconômico dos municípios mineiros?

Partindo da hipótese de que a eficiência fiscal dos municípios implica melhores indicadores sociais e que estes, por sua vez, impactam no desempenho socioeconômico, o objetivo deste artigo é identificar em que medida a composição da arrecadação tributária própria e os níveis de dependência das transferências intergovernamentais são associados ao desenvolvimento socioeconômico dos municípios de Minas Gerais.

Especificamente, pretende-se classificar e caracterizar os municípios segundo a composição das receitas tributárias em relação à receita total; verificar a existência de diferenças entre os municípios em relação aos estratos de potencial arrecadatório e identificar a associação da composição das receitas municipais no desenvolvimento socioeconômico dos municípios mineiros.

Dessa forma, o trabalho se justifica pela importância de se identificar a influência da composição das receitas tributárias municipais no desempenho socioeconômico dos municípios, visto que a literatura aborda questões relacionadas às dificuldades na gestão de recursos municipais, mas é incipiente quanto à relação destes com o desenvolvimento.

Além dessa introdução, este texto é composto por referencial teórico - abordando o federalismo fiscal brasileiro, o desenvolvimento socioeconômico no federalismo e as finanças públicas -, procedimentos metodológicos, resultados e discussão, considerações finais e referências bibliográficas.

\section{REFERENCIAL TEÓRICO}

\section{Federalismo Fiscal Brasileiro}

Para que o Estado consiga aplicar seus recursos agregando valor à sociedade, é necessário que sua atividade financeira seja feita como estabelece a regra, seguindo o que regulamentam as legislações e visando ao 
desenvolvimento conjunto das áreas. Quanto ao sistema federativo e suas peculiaridades, há que se destacar o fenômeno da descentralização gerado pela repartição das responsabilidades das unidades federativas de um Estado.

De acordo com Kappeler e Välilä (2008), a teoria tradicional do federalismo fiscal é baseada nas contribuições seminais de Tiebout (1956), Oates (1972) e Musgrave (1959), que tratam da atribuição de competências ideais entre os níveis de governo de acordo com a capacidade de resposta às preferências locais. Tal capacidade implica a descentralização e a concorrência fiscal, que são preferíveis na provisão de bens públicos locais, uma vez que existem diferenças entre as prioridades de cada localidade (KAPPELER; VÄLILÄ, 2008).

Nazareth (2007) destaca as peculiaridades existentes entre as formas de federalismo, revelando as dificuldades associadas a uma teoria do federalismo, devido à inexistência de um modelo único, diferindo de país para país de acordo com fatores históricos, culturais e econômicos.

De acordo com Oates (2005), na teoria do federalismo fiscal existem duas abordagens, denominadas de Teorias do Federalismo Fiscal de Primeira e de Segunda Geração. O foco de análise das Teorias de Primeira Geração é principalmente a atribuição de funções aos diferentes níveis de governo; já as Teorias de Segunda Geração caracterizam-se, sobretudo, pela responsabilidade fiscal a que está sujeito o sistema subnacional (OATES, 2005; WEINGAST, 2009; AGUIAR, 2011).

No caso brasileiro, desde sua origem, mais especificamente na Constituição Federal de 1891, a Federação brasileira adotou o regime de separação de fontes tributárias, discriminando os tributos que seriam de competências exclusivas dos Estados e da União (ARRETCHE, 2004). Os municípios só vieram a adquirir competências exclusivas para decretar tributos a partir da Constituição de 1934, relativos apenas aos impostos prediais, licenças e taxas de serviços municipais. 
A partir disso, o avanço da estrutura tributária nacional, no que diz respeito principalmente à distribuição de competências entre os entes federativos, ocorreu lentamente, com as maiores mudanças sendo operadas pela centralização da Reforma Tributária do regime militar (1965-1968) e a descentralização fiscal impulsionada pela Constituição de 1988 (ARRETCHE, 2004).

A descentralização parcial no Brasil visou, entre outras medidas, a uma maior distribuição de recursos entre os entes federativos, porém não garantiu uma melhoria nos níveis de desigualdade entre os Estados e municípios do país (COSTA et al., 2011).

De acordo com Giambiagi e Além (2000), existem razões diversas encontradas para justificar o processo de descentralização fiscal, as quais são classificadas em três fatores: econômicos; culturais; políticos e institucionais e geográficos.

Os fatores econômicos estão associados à busca de uma alocação de recursos mais eficiente, sendo possível quando os bens e serviços públicos locais são fornecidos pelas esferas de governo mais próximas dos beneficiários; quanto aos fatores culturais políticos e institucionais, a descentralização pode contribuir para o envolvimento dos cidadãos na determinação do rumo da comunidade, reforçando, com isso, a transparência das ações do governo. Os fatores geográficos, por sua vez, justificam o processo de descentralização na medida em que, em um país caracterizado por grandes dimensões, torna-se mais fácil para os governos subnacionais atenderem às demandas da população (GIAMBIAGI; ALÉM, 2000).

Apesar da possibilidade de aumentar a receita disponível por intermédio da arrecadação própria, o que se nota é que muitos Estados e municípios não têm demonstrado interesse em aumentar suas arrecadações, devido ao "caronismo fiscal" que os faz receber um volume significativo de recursos fiscais com baixo esforço (COSTA et al., 2011). 
Esse fenômeno é chamado por Clementino (1998, apud COSTA et al., 2011) de "preguiça fiscal”, que consiste na falta de vontade política dos governantes locais em efetivar a potencialidade dos instrumentos tributários de que dispõem, no intuito de melhorar o sistema de arrecadação. Tal situação leva à dependência dos governos locais em relação ao governo central, podendo comprometer as finanças públicas municipais.

Costa et al. (2011) destacam alguns aspectos determinantes para que os Estados se mantenham sempre dependentes das transferências oriundas do governo central, por exemplo, a dificuldade de desenvolver atividades econômicas em escala necessária para propiciar uma ampliação na arrecadação própria e, por conseguinte, reduzir a dependência em relação às transferências oriundas da União.

Desse modo, embora os municípios tenham aumentado sua receita disponível após a reforma constitucional, a necessidade das transferências intergovernamentais também aumentou, uma vez que consiste em um dos principais mecanismos utilizados pelo governo para minimizar as disparidades regionais existentes entre os membros da Federação.

\section{Desenvolvimento Socioeconômico no Federalismo}

A questão do desenvolvimento socioeconômico no ambiente federativo já vem sendo explorada na literatura nacional e internacional há bastante tempo. Diversas são as abordagens, passando por concentração de renda, dependência fiscal, disparidades inter-regionais, entre outras (MYRDAL, 1968; SOUZA, 1998; KERBAUY, 2001; SANTOS, 2002; MEDEIROS, 2004; OLIVEIRA, 2008; SEPULVEDA; MARTINEZ-VAZQUEZ, 2011).

A provisão de serviços e bens à sociedade é uma das funções centrais do Estado (MUSGRAVE; MUSGRAVE, 1980) e é sobre o financiamento desse papel que se debruçam os estudos das finanças do setor público, que de um lado impõe um sistema de financiamento, baseado no pacto social, e 
de outro um sistema orçamentário baseado em um pacto federativo. Todos esses elementos visam a atender ao papel central do Estado de promoção do desenvolvimento socioeconômico e do bem-estar social.

O processo de desenvolvimento econômico e social, entretanto, não ocorre de maneira igual e simultânea em todos os locais de uma unidade federativa. Este processo se dá de forma irregular e, uma vez iniciado em determinados pontos, fortalece áreas mais dinâmicas que apresentam maior potencial de desenvolvimento (LIMA; SIMÕES, 2009).

É nesse contexto que o federalismo fiscal e administrativo cumpre papel fundamental na redução das disparidades e no incremento de regiões com níveis de desenvolvimento considerados aquém do ideal (EZCURRA; PASCUAL, 2008; SEPULVEDA; MARTINEZ-VASQUEZ, 2011). Esse esforço, todavia, tem duas faces próprias, materializadas por dimensões complementares, a saber: a econômica e a social.

A expressão desenvolvimento socioeconômico, como abordado neste trabalho, nasce da ideia de equalização dessas dimensões. Isso porque a expressão desenvolvimento social foi cunhada como alternativa de complementação à visão neoclássica de crescimento, cuja única dimensão considerada era a econômica. Logo a introdução de uma dimensão social viria para equalizar elementos de contribuição social para além do que era possível ser mensurado pela economia.

Como colocado por Siedenberg (2003) apesar de haver certo consenso sobre a necessidade de complementar os dados econômicos com alguns aspectos sociais, ao se falar em desenvolvimento, nem sempre houve unanimidade em torno do assunto. Por muito tempo, mensuradores econômicos como PIB, renda per capita dentre outros eram usados como proxies de desenvolvimento.

Hoje há um consenso de uso de indicadores que consideram as duas dimensões na construção da análise, como adotado nesse trabalho. As razões centrais, expostas por Siedenberg (2003) para o uso dos indicadores socioe- 
conômicos, estão alinhadas com a proposta desse trabalho, à medida que são intervenientes para o alcance do objetivo geral do trabalho, sendo elas: a) diagnosticar as condições de desenvolvimento social ou setorial; b) propiciar informações sobre problemas sociais ou crises potenciais; c) subsidiar planos e decisões políticas; d) avaliar metas e estratégias globais/setoriais.

Esses são elementos centrais para a instituição de qualquer política pública de cunho fiscal ou orçamentário, que tem no bojo o ambiente federativo e no rompimento ou mitigação das desigualdades sua estratégia de ação.

Como o governo tem um papel estabilizador e de promoção econômica e social, suas políticas fiscais, tributárias e macroeconômicas devem observar essa função, em especial no estabelecimento das normativas que ordenam as transferências interfederativas.

Conforme ressaltado por Costa et al. (2012), são justamente as disparidades nos fundamentos econômicos e sociais, presentes no Brasil desde o início de sua História, que condicionam a emergência de diferentes níveis de desenvolvimento socioeconômico regionais.

Nessa direção e visando à garantia de boas condições socioeconômicas para todas as regiões, o Estado descentraliza tanto ações quanto recursos. No caso brasileiro, essa descentralização fiscal e administrativa foi consolidada pela Constituição de 1988, conferindo aos municípios maior autonomia na gestão de recursos e na instituição de políticas públicas sobre sua jurisdição.

Para Affonso (1994), a organização em unidades da Federação implica a transferência significativa de recursos públicos entre regiões com desigual capacidade econômica e com grandes assimetrias sociais. Logo, torna lícito na composição deste trabalho o uso de indicadores socioeconômicos como forma de se aquilatar o grau de cumprimento desse papel público. 


\section{Finanças Públicas}

As finanças públicas, de maneira geral, estão fundamentadas na existência das falhas de mercado, do estudo das funções do governo, da tributação e do gasto público.

Segundo o que versa a teoria do bem-estar social, sob determinadas condições, os mercados competitivos tendem a gerar uma alocação de recursos que se caracteriza pelo fato de que é impossível promover uma realocação de recursos de tal modo que um indivíduo aumente o seu grau de satisfação sem que, ao mesmo tempo, degrade a situação de outro indivíduo qualquer (TÁMEZ; MORAES JUNIOR, 2007).

Posto isso, na tentativa de amenizar essas falhas de mercado, o Estado desempenha importante papel na sociedade, quando guia, corrige e complementa o complexo sistema de mercado (GIAMBIAGI; ALÉM, 2000).

De acordo com Rezende (2001), as funções do Estado se expandiram consideravelmente devido à necessidade de intervenção na economia e na sociedade. Ao longo da História, modificaram-se substancialmente, pois anteriormente eram responsáveis apenas pela manutenção de serviços sociais básicos, como segurança e justiça, cabendo e ele atualmente a responsabilidade por manter serviços na área de saúde, educação e infraestrutura, bem como ser um agente regulador da economia.

Nesse sentido, Giambiagi e Além (2000) ressaltam as três funções básicas do Estado: a função alocativa, em que o fornecimento dos bens públicos é tratado; a função distributiva, que diz respeito à justa distribuição de renda e seus ajustes, e a função estabilizadora, que objetiva bons níveis de desempenho da economia como um todo, por meio da utilização da política econômica.

Para Musgrave e Musgrave (1980),

a função alocativa diz respeito à alocação de recursos pela atividade estatal, quando não houver eficiência da iniciativa privada ou quando a natureza da atividade indicar a necessidade da presença do Estado. É o 
processo pelo qual o governo divide os recursos para utilização no setor público e privado, oferecendo bens públicos, semipúblicos ou meritórios, como rodovias, segurança, educação, saúde, entre outros, aos cidadãos.

Musgrave e Musgrave (1980) compreendem que o objetivo da função distributiva é proporcionar uma distribuição mais equilibrada de renda e riqueza a toda a população, tentando corrigir as diferenças ocasionadas pela imperfeição do mercado. Essa função permite ao governo realizar ajustes na distribuição de renda, de modo a torná-la mais justa.

Por fim, a função estabilizadora é pautada nos objetivos macroeconômicos de manutenção do elevado nível de emprego, estabilidade nos níveis de preços, equilíbrio no balanço de pagamentos e razoável taxa de crescimento econômico, o que, na ausência de uma política orientadora, faria com que a economia ficasse sob riscos relacionados às flutuações de renda, emprego e inflação (MUSGRAVE; MUSGRAVE, 1980).

A garantia do desenvolvimento nacional, da erradicação da pobreza e a marginalização e a redução das desigualdades sociais e regionais constam como um dos objetivos fundamentais na Constituição Federal de 1988. Para o alcance de tais objetivos é necessário que o Estado disponha de recursos suficientes para financiar os bens e serviços públicos demandados pela sociedade. Posto isso, o governo possui como principal fonte de receita a arrecadação de tributos.

Segundo Matias-Pereira (2009), o objeto precípuo das finanças públicas de um Estado é a atividade fiscal desempenhada com o propósito de obter e aplicar recursos para o custeio dos serviços disponibilizados aos cidadãos, sendo orientada segundo duas direções: a) política tributária, que se materializa na captação de recursos, para atendimento das funções da Administração Pública; b) política orçamentária, que se refere especificamente aos gastos, ou seja, aos atos e medidas relacionados com a forma da 
aplicação dos recursos, levando em consideração a dimensão e a natureza das atribuições do poder público, bem como a capacidade e a disposição para seu financiamento pela população.

Assim, por meio das suas atribuições alocativa, distributiva e estabilizadora, o governo utiliza a tributação como uma ferramenta relevante de promoção do crescimento econômico e de redução das desigualdades existentes (TÁMEZ; MORAES JUNIOR, 2007).

\section{Procedimentos Metodológicos}

\section{Tipo de Pesquisa}

O presente trabalho classifica-se como de caráter descritivo, pois são relatadas as informações coletadas e a relação entre a composição da arrecadação tributária municipal e o nível de transferências com o desenvolvimento socioeconômico dos municípios de Minas Gerais (SAMPIERI; COLLADO; LUCIO, 2006).

Quanto à operacionalização, foi realizada pesquisa documental, buscando-se, por meio do levantamento das variáveis financeiras e socioeconômicas dos municípios mineiros, obter maior conhecimento sobre o tema e o problema de pesquisa. Em relação à natureza dos dados, são do tipo secundário, por terem sido coletados anteriormente para finalidades diversas e já disponibilizados. Deste modo, este artigo caracteriza-se como uma pesquisa quantitativa, tendo como objeto de estudo os dados financeiros e socioeconômicos dos municípios mineiros.

\section{Área de Estudo}

A área de abrangência deste estudo é o Estado de Minas Gerais que, segundo dados do IBGE de 2012, possui o maior número de municípios entre os Estados brasileiros, 853, sendo o segundo mais populoso, com 19.597.330 de habitantes, respondendo pela terceira maior economia do Brasil. 
Importa destacar que, apesar de ter recebido o segundo maior montante em receitas correntes no ano de 2012, Minas Gerais foi o Estado brasileiro que deteve, por município, o quinto menor índice de arrecadação própria e o sétimo menor nível de transferências recebidas, de acordo com o Finbra.

Nesse contexto, a escolha deste Estado se justifica pelo fato de refletir a conjuntura nacional, retratando a diversidade do processo de desenvolvimento socioeconômico brasileiro, sendo marcado por diferenças econômicas, sociais e de finanças públicas (COSTA et al., 2012).

Conforme dados do Banco Nacional do Desenvolvimento Econômico e Social (BNDES) do ano de 2000, citado por Delgado e Machado (2007), o Estado é reconhecido como um caso ilustrativo das desigualdades sociorregionais presentes no Brasil, permitindo extrapolações e futura aplicação ao caso brasileiro.

\section{Fonte de Dados e Identificação das Variáveis}

Foram coletados neste estudo dados secundários referentes ao orçamento, demografia, economia, renda, saúde, educação, infraestrutura e desenvolvimento, conforme apresentado pelo Quadro 1.

Quadro 1 - Fontes dos dados secundários - Dados de 2010

\begin{tabular}{|l|l|}
\hline \multicolumn{1}{|c|}{ Dados } & \multicolumn{1}{c|}{ Fontes } \\
\hline Orçamento & $\begin{array}{l}\text { Finanças do Brasil, Dados Contábeis dos Municípios - Finbra, dis- } \\
\text { poníveis na Secretaria do Tesouro Nacional. }\end{array}$ \\
\hline Demografia & $\begin{array}{l}\text { Atlas do Desenvolvimento Humano no Brasil - Programa Nações } \\
\text { Unidos para o Desenvolvimento (Pnud) e } \\
\text { Instituto Brasileiro de Geografia e Estatística (IBGE) }\end{array}$ \\
\hline $\begin{array}{l}\text { Economia, renda, } \\
\text { saúde, educação e in- } \\
\text { fraestrutura. }\end{array}$ & Índice Mineiro de Responsabilidade Social (IMRS) \\
\hline Desenvolvimento & Sistema Firjan \\
\hline
\end{tabular}

Fonte: Elaborado pelos autores. 
As informações compreenderam o ano de 2010, devido à indisponibilidade dos dados financeiros e de desenvolvimento socioeconômico de anos mais recentes. Ressalta-se, ainda, que as informações financeiras foram deflacionadas pelo Índice Nacional de Preços ao Consumidor Amplo (IPCA) para o ano de 2014.

\section{Operacionalização e Tratamento dos Dados}

Primeiramente, procedeu-se à classificação dos municípios mineiros considerando a participação das receitas próprias na composição de suas receitas totais, sendo estes agrupados de acordo com o desempenho do potencial de arrecadação.

O agrupamento foi feito a partir do desvio padrão em torno da média do referido indicador de desempenho, ressaltando-se que os que apresentaram proporções similares foram classificados no mesmo grupo. Como critério de classificação os municípios foram agrupados pela variação de meio e um desvio padrão abaixo e acima da média, dando origem a cinco estratos.

Além disso, no intuito de caracterizar os grupos formados, foi efetuada a Análise Exploratória de Dados (AED), com a apresentação das medidas de tendência central das variáveis demonstradas pelo Quadro 2.

Quadro 2 - Variáveis para caracterização dos grupos - Dados de 2010

\begin{tabular}{|l|l|}
\hline \multicolumn{1}{|c|}{ VARIÁVEIS } & \multicolumn{1}{c|}{ Expectativa Teórica } \\
\hline População & $\begin{array}{l}\text { Municípios de maior porte têm maior potencial } \\
\text { arrecadatório }\end{array}$ \\
\hline $\begin{array}{l}\text { Índice Firjan de Desenvolvi- } \\
\text { mento Municipal (IFDM) }\end{array}$ & $\begin{array}{l}\text { Maior potencial arrecadatório implica melhores } \\
\text { índices de desenvolvimento }\end{array}$ \\
\hline Renda per capita & $\begin{array}{l}\text { Bases diversificadas de tributação implicam } \\
\text { melhores níveis de renda da população }\end{array}$ \\
\hline
\end{tabular}




\begin{tabular}{|c|c|}
\hline Arrecadação ISS per capita & \multirow{4}{*}{$\begin{array}{l}\text { Níveis de tributos próprios arrecadados são } \\
\text { diretamente proporcionais ao aumento no } \\
\text { percentual de receitas próprias }\end{array}$} \\
\hline Arrecadação IPTU per capita & \\
\hline Arrecadação ITBI per capita & \\
\hline Arrecadação Taxas per capita & \\
\hline $\begin{array}{l}\text { Valor Adicionado Fiscal per } \\
\text { capita-Atividades Primárias }\end{array}$ & \multirow{3}{*}{$\begin{array}{l}\text { O potencial de geração de receitas, por setor, } \\
\text { implica maior desenvolvimento, melhor estru- } \\
\text { tura tributária e, consequentemente, nível de } \\
\text { potencial arrecadatório mais alto }\end{array}$} \\
\hline $\begin{array}{l}\text { Valor Adicionado Fiscal per } \\
\text { capita-Indústria }\end{array}$ & \\
\hline $\begin{array}{l}\text { Valor Adicionado Fiscal per } \\
\text { capita-Serviços }\end{array}$ & \\
\hline
\end{tabular}

Fonte: Elaborado pelos autores.

De acordo com Triola (2008), a Análise Exploratória de Dados (AED) é utilizada para investigação de conjuntos de dados com o objetivo de se compreender suas características importantes, em que são utilizadas ferramentas estatísticas (tais como gráficos, medidas de centro e medidas de variação). Assim, a AED tem por finalidade o exame prévio dos dados, a fim de organizá-los e sintetizá-los, para familiarizar-se com eles e, assim, entender seu comportamento.

A fim de identificar a existência de diferenças entre os municípios no que se refere ao potencial arrecadatório, efetuou-se a análise de variância (Anova) para testar a diferença de médias entre os estratos formados.

O teste de média é utilizado para análise estatística, que pode ser realizado com uma, duas, três ou mais amostras. Para Bruni (2009, p. 148), "o teste de uma amostra para médias é característico de situações em que se procura testar alguma afirmação sobre o parâmetro média da população”. Já para o teste de duas amostras, se "deseja decidir se um grupo é diferente de outro". Para um teste de três ou mais amostras pode ser utilizada a análise de variância (Anova) como "um método para se testar a igualdade de três ou mais médias populacionais através da análise das variâncias amostrais" (TRIOLA, 2008, p. 508). 
Ainda segundo Triola (2008, p. 509), a Anova "se baseia na comparação de duas estimativas diferentes da variância comum de duas populações diferentes". Além disso, o autor ressalta que "o termo de um fator é usado porque os dados amostrais são separados em grupos de acordo com uma característica, ou fator" (p. 509).

Ressalta-se que, para serem validados, os grupos obtidos devem apresentar uma alta homogeneidade interna e uma alta heterogeneidade externa (HAIR et al., 2009). Assim, foi calculado pelo teste Anova a existência estatisticamente significativa de diferenças de médias entre os estratos de potencial arrecadatório.

Com o propósito de identificar a interferência da composição da arrecadação própria no desenvolvimento socioeconômico dos municípios mineiros, empregou-se o teste Qui-Quadrado, definido como uma medida de discrepância existente entre frequências observadas e esperadas, para testar a independência entre os estratos de potencial arrecadatório e de desenvolvimento socioeconômico (REGAZZI, 2007).

Segundo Regazzi (2007), o teste Qui-Quadrado pode ser usado principalmente como: teste de aderência, para comprovar o ajustamento de uma função de frequência a dados de observação; teste de independência, usado em conexão com as tabelas de contingência, elaboradas com o propósito de se estudar a relação de dependência entre duas variáveis; e teste de homogeneidade, em que uma das variáveis praticamente representa uma classificação dos elementos em populações distintas.

Desse modo, os estratos de desenvolvimento municipal, juntamente aos grupos de potencial arrecadatório, foram utilizados para a realização da tabulação cruzada e do teste Qui-Quadrado, no intuito de verificar a independência entre eles. 
Para a formação dos estratos de desenvolvimento socioeconômico, utilizou-se o Índice Firjan de Desenvolvimento Municipal (IFDM) de 2010. Tal indicador, calculado anualmente pelo Sistema Firjan, possibilita identificar o desenvolvimento socioeconômico dos municípios em três áreas de atuação: Emprego e Renda, Educação e Saúde.

Para classificar o nível de desenvolvimento de cada localidade, o IFDM varia de 0 a 1 , e quanto mais próximo de 1 , maior o desenvolvimento municipal. Optou-se pela utilização desse indicador, em detrimento do Índice de Desenvolvimento Humano (IDH), mais comumente utilizado, visto que o IFDM é calculado anualmente, e o IDH municipal é calculado com base em dados censitários apenas a cada dez anos.

No teste Qui-Quadrado, a Hipótese $\mathrm{H}_{1}$, que é a hipótese de dependência das variáveis testadas, é aceita sempre que o teste for inferior a 0,05 . Nesse teste, para tirar conclusões sobre a relação existente entre as variáveis, os valores esperados de todas as células são comparados com seus respectivos valores observados.

Assim, neste estudo são levantadas as seguintes hipóteses relacionadas à independência dos estratos de potencial arrecadatório e desenvolvimento municipal:

$H_{0}$ : Os estratos são independentes entre si.

$H_{1}$ : Os estratos não são independentes entre si.

\section{Resultados E Discussão}

\section{Classificação e Análise Exploratória dos Dados}

A estratificação dos 853 municípios mineiros foi efetuada considerando o potencial de arrecadação, apurado entre a relação da receita tributária e a receita corrente dos municípios, que em média apresentaram a relação percentual de $5,74 \%$ e desvio padrão de $4,81 \%$. O potencial de arrecada- 
ção foi utilizado para hierarquizar os municípios quanto a sua capacidade arrecadatória. Para que a formação dos grupos mantivesse características homogêneas, utilizou-se como critério de classificação a variação de meio e um desvio padrão para mais e para menos, que deu origem a cinco estratos. Um destes estratos foi formado por dois municípios de baixo potencial arrecadatório, que posteriormente foram agrupados em estrato semelhante, conforme disposto no Quadro 3.

Observa-se que a maior parte dos municípios se enquadra no estrato de potencial moderado baixo e baixo potencial de arrecadação, totalizando 688 , representando $80,66 \%$ do total, enquanto $7,62 \%$ apresentam potencial moderado alto e $11,72 \%$ mostram elevado potencial arrecadatório. O município de Monte Formoso, localizado na Mesorregião do Jequitinhonha, com renda per capita de $\mathrm{R} \$ 297,82$ apresentou o menor índice de potencial de arrecadação, 0,34\%, e o município de Jeceaba, da Mesorregião Metropolitana de Belo Horizonte, com renda per capita de $\mathrm{R} \$ 499,19$ apresentou o índice de $69,25 \%$, destacando-se como o município de maior poder arrecadatório.

Quadro 3 - Classificação dos municípios mineiros de acordo com o Potencial Arrecadatório

\begin{tabular}{|l|c|c|c|}
\hline \multicolumn{1}{|c|}{ Estrato arrecadatório } & Municípios & $\begin{array}{c}\text { Participação } \\
\text { Percentual }\end{array}$ & $\begin{array}{c}\text { Escala de } \\
\text { Classificação }\end{array}$ \\
\hline Baixo Potencial & 291 & 34,12 & $\begin{array}{c}\text { Abaixo de } \\
3,34 \%\end{array}$ \\
\hline Potencial Moderado Baixo & 397 & 46,54 & $\begin{array}{c}\text { Entre } 3,34 \% \\
\text { e } 8,15 \%\end{array}$ \\
\hline Potencial Moderado Alto & 65 & 7,62 & $\begin{array}{c}\text { Entre } 8,15 \% \\
\text { e } 10,57 \%\end{array}$ \\
\hline Elevado Potencial & 100 & 11,72 & $\begin{array}{c}\text { Acima de } \\
10,57 \%\end{array}$ \\
\hline
\end{tabular}

Fonte: Elaborado pelos autores. 
O cenário observado pela Figura 1 retrata a distribuição econômica no Estado, evidenciando certa diversidade em função de questões territoriais.

Figura 1 - Distribuição espacial dos municípios mineiros em relação ao potencial de arrecadação

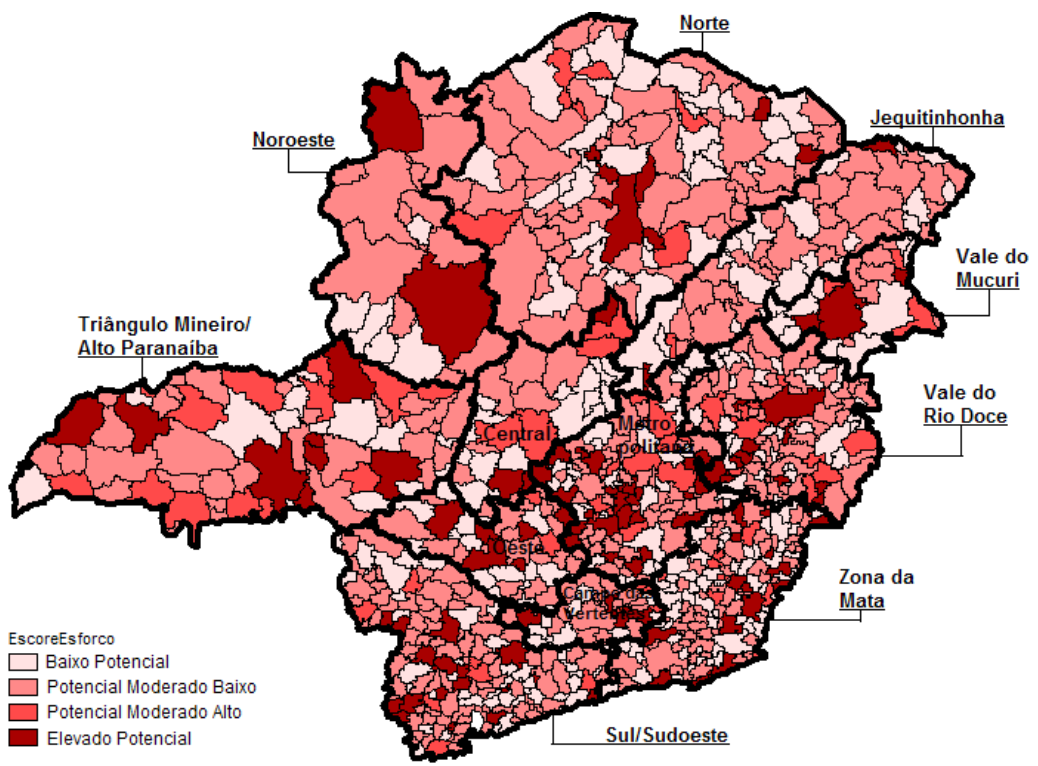

Fonte: Elaborada pelos autores.

Considerando-se que as fontes de recursos para sustentação financeira dos municípios são formadas por recursos próprios arrecadados e transferências intergovernamentais, observa-se que grande parte dos municípios apresenta capacidade financeira distinta, dado que na maioria dos municípios as transferências representam a maior fonte de receita orçamentária.

Para Musgrave (1974), quanto maiores forem as rendas percapita e do grupo, maior será presumivelmente, a capacidade de tributação ou a possibilidade de contribuição. Este fato pode ser constatado na Tabela 1, na qual é possível verificar que as mesorregiões que apresentam baixo e moderado potencial de arrecadação possuem a renda per capita média menor, a exemplo das Mesorregiões do Jequitinhonha, Norte de Minas e Vale do Mucuri. 
Tabela 1 - Distribuição dos municípios por estrato e mesorregião

\begin{tabular}{|c|c|c|c|c|c|c|}
\hline \multirow[b]{2}{*}{ Mesorregião } & \multirow[b]{2}{*}{$\begin{array}{l}\mathrm{N}^{\mathrm{o}} \mathrm{de} \\
\text { muni- } \\
\text { cípios }\end{array}$} & \multicolumn{5}{|c|}{ Estratos } \\
\hline & & $\begin{array}{c}\text { Renda } \\
\text { per capita } \\
\text { Média }\end{array}$ & $\begin{array}{c}\text { Baixo } \\
\text { Poten- } \\
\text { cial }\end{array}$ & $\begin{array}{c}\text { Poten- } \\
\text { cial Mo- } \\
\text { derado } \\
\text { Baixo }\end{array}$ & $\begin{array}{c}\text { Po- } \\
\text { tencial } \\
\text { Modera- } \\
\text { do Alto }\end{array}$ & $\begin{array}{c}\text { Elevado } \\
\text { Poten- } \\
\text { cial }\end{array}$ \\
\hline Campo das Vertentes & 36 & 560,55 & $47,22 \%$ & $36,11 \%$ & $11,11 \%$ & $5,56 \%$ \\
\hline Central Mineira & 30 & 595,32 & $36,67 \%$ & $30,00 \%$ & $20,00 \%$ & $13,33 \%$ \\
\hline Jequitinhonha & 51 & 383,50 & $37,25 \%$ & $58,82 \%$ & $3,92 \%$ & $0,00 \%$ \\
\hline $\begin{array}{l}\text { Metropolitana de } \\
\text { Belo Horizonte }\end{array}$ & 105 & 596,06 & $19,05 \%$ & $42,86 \%$ & $11,43 \%$ & $26,67 \%$ \\
\hline Noroeste de Minas & 19 & 573,16 & $10,53 \%$ & $63,16 \%$ & $0,00 \%$ & $26,32 \%$ \\
\hline Norte de Minas & 89 & 360,99 & $46,07 \%$ & $46,07 \%$ & $3,37 \%$ & $4,49 \%$ \\
\hline Oeste de Minas & 44 & 633,38 & $27,27 \%$ & $47,73 \%$ & $9,09 \%$ & $15,91 \%$ \\
\hline $\begin{array}{l}\text { Sul/Sudoeste de } \\
\text { Minas }\end{array}$ & 146 & 616,97 & $22,60 \%$ & $58,22 \%$ & $6,16 \%$ & $13,01 \%$ \\
\hline $\begin{array}{l}\text { Triângulo Mineiro/ } \\
\text { Alto Paranaíba }\end{array}$ & 66 & 713,20 & $13,64 \%$ & $53,03 \%$ & $18,18 \%$ & $15,15 \%$ \\
\hline Vale do Mucuri & 23 & 398,52 & $52,17 \%$ & $34,78 \%$ & $13,04 \%$ & $0,00 \%$ \\
\hline Vale do Rio Doce & 102 & 454,92 & $42,16 \%$ & $43,14 \%$ & $4,90 \%$ & $9,80 \%$ \\
\hline Zona da Mata & 142 & 527,46 & $50,00 \%$ & $38,73 \%$ & $3,52 \%$ & $7,75 \%$ \\
\hline
\end{tabular}

Fonte: Elaborada pelos autores.

Este resultado é corroborado por Siqueira (2014), que ao avaliar a eficiência tributária dos municípios pernambucanos identificou grande concentração de níveis maiores de arrecadação própria na região metropolitana e baixa arrecadação por parte das regiões periféricas do Estado. Tal fato ocorre devido ao fato de que as regiões metropolitanas são os principais polos econômicos dos Estados, tendo maiores níveis de atividade econômica e uma arrecadação significativamente superior à dos municípios de outras regiões (SIQUEIRA, 2014).

Constatou-se que altos níveis de atividade econômica tendem a ampliar a eficiência na arrecadação tributária, tendo os municípios com maiores rendas per capita maiores escores de eficiência. A caracterização dos estratos de potencial arrecadatório, em relação ao potencial econômico e de desenvolvimento, é apresentada na Tabela 2. 
Nestes estratos os indicadores relacionados com a população revelam um quadro heterogêneo na composição dos grupos, indicando relação direta entre o porte do município e o potencial de arrecadação em que municípios de maior porte e maior estrato populacional apresentam maior potencial arrecadatório. O contrário também é observado para os municípios de menor porte e menor estrato populacional. Este mesmo comportamento foi observado em relação à renda per capita.

Tabela 2 - Caracterização dos Estratos e relação do potencial de arrecadação às variáveis

\begin{tabular}{|c|c|c|c|c|c|c|}
\hline \multirow[t]{2}{*}{ VARIÁVEIS } & \multirow[t]{2}{*}{$\begin{array}{l}\text { Correlação } \\
\text { Ró de } \\
\text { Spearman }\end{array}$} & Medida & $\begin{array}{c}\text { Baixo } \\
\text { Potencial }\end{array}$ & \multirow{2}{*}{$\begin{array}{c}\text { Potencial } \\
\text { Moderado } \\
\text { Baixo }\end{array}$} & \multirow{2}{*}{ 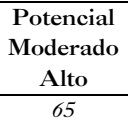 } & \multirow{2}{*}{$\begin{array}{c}\begin{array}{c}\text { Elevado } \\
\text { Potencial }\end{array} \\
100 \\
\end{array}$} \\
\hline & & Municípios & 290 & & & \\
\hline \multirow{3}{*}{ Renda per capita } & \multirow{3}{*}{0,539} & Média & 455,34 & 531,88 & 639,62 & 733,76 \\
\hline & & Mediana & 435,70 & 535,67 & 664,52 & 741,06 \\
\hline & & Desvio Padrão & 110,43 & 120,37 & 129,33 & 205,60 \\
\hline \multirow{3}{*}{ População } & \multirow{3}{*}{0,626} & Média & 6.02 & 12.435 & 38.249 & 104,224 \\
\hline & & Mediana & 4.93 & 9.490 & 23.043 & 45,442 \\
\hline & & Desvio Padrão & 4.19 & 10.217 & 53.764 & 255,325 \\
\hline \multirow{3}{*}{$\begin{array}{l}\text { Índice Firjan de } \\
\text { Desenvolvimento } \\
\text { Municipal (IFDM) }\end{array}$} & \multirow{3}{*}{0,433} & Média & 0,594 & 0,626 & 0,679 & 0,722 \\
\hline & & Mediana & 0,604 & 0,638 & 0,685 & 0,727 \\
\hline & & Desvio Padrão & 0,079 & 0,092 & 0,078 & 0,077 \\
\hline \multirow{3}{*}{$\begin{array}{l}\text { Arrecadação ISS } \\
\text { per capita }\end{array}$} & \multirow{3}{*}{0,741} & Média & 15,84 & 40,98 & 80,02 & 200,16 \\
\hline & & Mediana & 12,89 & 30,49 & 62,23 & 88,89 \\
\hline & & Desvio Padrão & 10,25 & 41,69 & 54,13 & 414,65 \\
\hline \multirow{3}{*}{$\begin{array}{l}\text { Arrecadação IPTU } \\
\text { per capita }\end{array}$} & \multirow{3}{*}{0,582} & Média & 4,19 & 10,03 & 20,53 & 46,17 \\
\hline & & Mediana & 2,88 & 7,11 & 17,87 & 31,62 \\
\hline & & Desvio Padrão & 4,34 & 8,92 & 14,28 & 51,82 \\
\hline \multirow{3}{*}{$\begin{array}{l}\text { Arrecadação ITBI } \\
\text { per capita }\end{array}$} & \multirow{3}{*}{0,551} & Média & 5,13 & 11,80 & 18,50 & 25,43 \\
\hline & & Mediana & 3,45 & 8,46 & 14,03 & 19,20 \\
\hline & & Desvio Padrão & 5,52 & 14,24 & 21,16 & 26,30 \\
\hline \multirow{3}{*}{$\begin{array}{l}\text { Arrecadação Taxas } \\
\text { per capita }\end{array}$} & \multirow{3}{*}{0,530} & Média & 4,13 & 8,72 & 15,23 & 23,97 \\
\hline & & Mediana & 2,88 & 6,60 & 14,72 & 17,27 \\
\hline & & Desvio Padrão & 4,06 & 8,16 & 9,70 & 21,95 \\
\hline \multirow{3}{*}{$\begin{array}{l}\text { VAF per cap } \\
\text { Atividades } \\
\text { Primárias }\end{array}$} & \multirow{3}{*}{$0,036^{*}$} & Média & 1,06 & 1,32 & 1,19 & 1,03 \\
\hline & & Mediana & 0,35 & 0,48 & 0,32 & 0,29 \\
\hline & & Desvio Padrão & 2,38 & 2,36 & 2,22 & 2,08 \\
\hline \multirow{3}{*}{$\begin{array}{l}\text { VAF per capita } \\
\text { Indústria }\end{array}$} & \multirow{3}{*}{0,546} & Média & 0,98 & 2,89 & 5,38 & 5,78 \\
\hline & & Mediana & 0,58 & 0,81 & 2,18 & 2,83 \\
\hline & & Desvio Padrão & 1,79 & 9,39 & 9,21 & 9,07 \\
\hline \multirow{3}{*}{$\begin{array}{l}\text { VAF per capita } \\
\text { Serviços }\end{array}$} & \multirow{3}{*}{0,504} & Média & 4,10 & 5,02 & 7,32 & 7,71 \\
\hline & & Mediana & 3,84 & 4,41 & 5,87 & 7,13 \\
\hline & & Desvio Padrão & 1,58 & 2,64 & 6,93 & 3,11 \\
\hline
\end{tabular}

* Indica que a correlação NÃO é estatisticamente significativa ao nível de $1 \%$

Fonte: Elaborada pelos autores. 
Avaliando o Índice Firjan de Desenvolvimento Municipal (IFDM), observou-se maior homogeneidade nos estratos, evidenciando a concentração de municípios com índices aproximados de desenvolvimento municipal em um mesmo grupo. Na metodologia do Sistema Firjan, o desempenho do índice é classificado em quatro níveis, sendo atribuído baixo desenvolvimento para resultados inferiores a 0,4 ponto; desenvolvimento regular, compreendido entre 0,4 e 0,6 ponto; desenvolvimento moderado, entre 0,6 e 0,8 ponto; e alto desenvolvimento, para resultados superiores a 0,8 ponto.

Em relação aos níveis de arrecadação per capita dos tributos municipais, constata-se a predominância de maior valor médio do ISS entre os estratos com maior potencial arrecadatório. Destaca-se uma maior variabilidade nas medidas de tendência central à medida que aumenta o potencial arrecadatório, principalmente em relação ao desvio padrão.

A capacidade econômica de um município pode ser constatada por meio do Valor Adicionado Fiscal - VAF - , que serve de base para os repasses constitucionais sobre os valores das receitas de impostos recolhidos pelos Estados e pela União, conforme fundamentado nos artigos 158 e 159 da Constituição Federal.

Observa-se, com exceção do VAF per capita das atividades primárias, que os VAFs relacionados com a indústria e os serviços apresentam maiores destaques no que se refere ao aumento do potencial arrecadatório dos municípios. Neste aspecto, regra geral, quanto mais alto for o índice aferido para o município, maior é o valor recebido, indicando que quanto maior a capacidade econômica do município, maior sua capacidade em auferir receitas.

Para Baião (2013), Transferências Incondicionais Devolutivas ${ }^{7}$ distribuem os recursos para os governos em que foi realizada a arrecadação, sem a presença de condicionalidades sobre a forma de gasto. Um exemplo

7 O governo central devolve ao Estado ou ao município os recursos que foram anteriormente arrecadados por eles. 
é o ICMS, em que no mínimo 75\% são distribuídos de acordo com o Valor Adicionado Fiscal (VAF) dos municípios. O VAF, neste caso, apresenta-se como uma proxy da base tributária do ICMS, e, portanto, até certo ponto indica quanto foi arrecadado do imposto no município.

Dessa forma percebe-se que as transferências intergovernamentais, em virtude do processo de descentralização, têm grande representatividade na composição arrecadatória dos municípios, principalmente daqueles de menor potencial econômico. Conforme constata Baião (2013), entretanto, estas parecem ter um efeito prejudicial no âmbito da equalização, favorecendo também municípios que já possuem maior capacidade de gerar arrecadação tributária.

\section{Potencial de Arrecadação dos Municípios e Composição da Arrecadação Própria}

Para atender aos objetivos deste estudo, foi realizado o teste Anova nos estratos formados pelo potencial de arrecadação dos municípios, a fim de identificar a existência de diferença das médias entre eles, relacionadas às variáveis arrecadação própria per capita dos tributos ISS, IPTU, ITBI e Taxas.

A Tabela 3 apresenta o cruzamento dos quatro estratos de potencial de arrecadação, evidenciando o distanciamento, entre grupos, das médias de cada variável. 
Tabela 3 - Diferença de médias entre os estratos de potencial de arrecadação

\begin{tabular}{|c|c|c|c|c|}
\hline & & \\
\hline & & $\begin{array}{c}\text { Moderado } \\
\text { Baixo }\end{array}$ & $\begin{array}{c}\text { Moderado } \\
\text { Alto }\end{array}$ & Elevado \\
\hline \multirow{5}{*}{ 离 } & Potencial Arrecadação & 0,029 & 0,070 & 0,132 \\
\hline & ISS per capita & $25,135^{\mathrm{ns}}$ & 64,183 & 184,323 \\
\hline & IPTU per capita & 5,844 & 16,339 & 41,978 \\
\hline & ITBI per capita & 6,663 & 13,365 & 20,298 \\
\hline & Taxas per capita & 4,590 & 11,103 & 19,838 \\
\hline \multirow{5}{*}{ 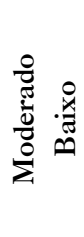 } & Potencial Arrecadação & & 0,041 & 0,102 \\
\hline & ISS per capita & & $39,048^{\text {ns }}$ & 159,188 \\
\hline & IPTU per capita & & 10,496 & 36,134 \\
\hline & ITBI per capita & & 6,701 & 13,635 \\
\hline & Taxas per capita & & 6,514 & 15,248 \\
\hline \multirow{5}{*}{ 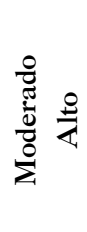 } & Potencial Arrecadação & & & 0,062 \\
\hline & ISS per capita & & & 120,139 \\
\hline & IPTU per capita & & & 25,639 \\
\hline & ITBI per capita & & & 6,934 \\
\hline & Taxas per capita & & & 8,735 \\
\hline
\end{tabular}

ns Não há significância estatística ao nível de 10\%.

Fonte: Resultados da Pesquisa.

De acordo com as estatísticas da análise de variância (Anova), a diferença entre médias apresentou-se estatisticamente significativa (ao nível de 10\%) para grande parte das variáveis relacionadas com a arrecadação própria. Este mesmo padrão não foi observado para a variável ISS per capita para os municípios enquadrados nos estratos de Baixo Potencial e Potencial Moderado Baixo, e, entre este último com o de Potencial Moderado Alto. 
Esta constatação pode ser explicada, em parte, considerando o trabalho de Orair e Alencar (2010), que, ao analisarem a evolução das receitas dos municípios brasileiros entre 2000 e 2009, identificaram um incremento importante na arrecadação de ISS dos municípios, com aumento mais expressivo nos pequenos municípios, que geralmente também são os mais pobres.

Para Souza (2007), entretanto, esta arrecadação está concentrada nos grandes centros e nas regiões mais desenvolvidas, nas quais se encontram as propriedades mais valorizadas, bem como grande parte das atividades de comércio e serviços. Isso implica maior arrecadação própria desses municípios, uma vez que os tributos de competência municipal incidem, principalmente, sobre o valor venal dos imóveis (IPTU e ITBI) e sobre a prestação de serviços (ISS).

Adicionalmente, todas as demais variáveis foram consideradas significativas, podendo-se inferir que há mudanças entre as médias destes estratos, rejeitando-se a hipótese nula de que existe igualdade entre as médias, o que permite inferir pela alta homogeneidade interna e alta heterogeneidade externa entre os estratos.

Esta constatação pode ser confirmada no trabalho de Souza (2007) que, ao avaliar o esforço fiscal e alocação de recursos nos municípios da Zona da Mata de Minas Gerais, observou que a arrecadação de um dos impostos mais significativos na composição da receita municipal própria, o IPTU, é diretamente relacionado com a faixa populacional dos municípios.

Constatação semelhante foi efetuada por Massardi (2014), que verificou que, apesar de os municípios de Minas Gerais terem aumentado sua capacidade fiscal via transferências intergovernamentais, o desenvolvimento ocorreu de forma heterogênea entre eles, uma vez que houve favorecimento dos municípios mais desenvolvidos, devido à base 
de incidência tributária de competência municipal. Fato semelhante, segundo o referido autor, aconteceu com os mecanismos de arrecadação própria de competência dos municípios, ao considerar que seus principais impostos, como o IPTU e ISS, possuem arrecadação mais potencializada em grandes centros e arrecadação menor nos centros menos dinâmicos e/ou de menor renda per capita.

Dessa forma, pode-se supor que os estratos são formados por municípios que apresentam perfis de arrecadação estatisticamente semelhantes, o que, mesmo com a exceção da arrecadação per capita de ISS, torna possíveis generalizações e constatações sobre características inerentes aos grupos.

\section{Potencial de Arrecadação e Desenvolvimento Municipal}

Para identificar a interferência da composição da arrecadação própria no desenvolvimento socioeconômico dos municípios mineiros, eles foram estratificados usando como proxy o Índice Firjan de Desenvolvimento Municipal - IFDM.-., que apresentou, em 2010, índice médio de 0,63 e desvio padrão de 0,09. Para que a formação dos grupos mantivesse características homogêneas, utilizou-se como critério de classificação a variação de meio e um desvio padrão para mais e para menos, que deu origem a cinco estratos, conforme disposto no Quadro 4.

Com a exceção do estrato de médio desenvolvimento, observa-se determinado equilíbrio na composição do número de municípios nos outros estratos, com 30,01\% dos municípios sendo classificados na extremidade dos estrados relacionados ao baixo grau de desenvolvimento socioeconômico. $\mathrm{Na}$ outra extremidade concentram-se $32,48 \%$ dos municípios com o potencial de desenvolvimento acima da média. 
Quadro 4 - Estratificação dos municípios mineiros em relação ao desenvolvimento socioeconômico

\begin{tabular}{|l|c|c|c|}
\hline Estrato de desenvolvimento & Municípios & $\begin{array}{c}\text { Participação } \\
\text { Percentual }\end{array}$ & $\begin{array}{c}\text { Escala de } \\
\text { Classificação }\end{array}$ \\
\hline Muito Baixo & 137 & 16,06 & Abaixo de 0,540 \\
Baixo & 119 & 13,95 & 0,541 a 0,586 \\
Médio & 320 & 37,51 & 0,587 a 0,678 \\
Alto & 149 & 17,47 & 0,679 a 0,724 \\
Muito Alto & 128 & 15,01 & Acima de 0,725 \\
\hline
\end{tabular}

Fonte: Elaborado pelos autores.

Considerando a estratificação efetuada, observa-se, pela Figura 2, a concentração de municípios de baixo potencial de desenvolvimento socioeconômico nas Mesorregiões do Jequitinhonha, Norte de Minas e Vale do Rio Doce, que também apresentaram baixa renda per capita e baixo potencial arrecadatório. Ao contrário, observa-se nas Mesorregiões Metropolitana, Sul/ Sudoeste e Triângulo Mineiro/Alto Paranaíba a concentração de municípios com maiores indicadores de desenvolvimento. 
Figura 1 - Distribuição espacial dos municípios mineiros em relação à estratificação do IFDM

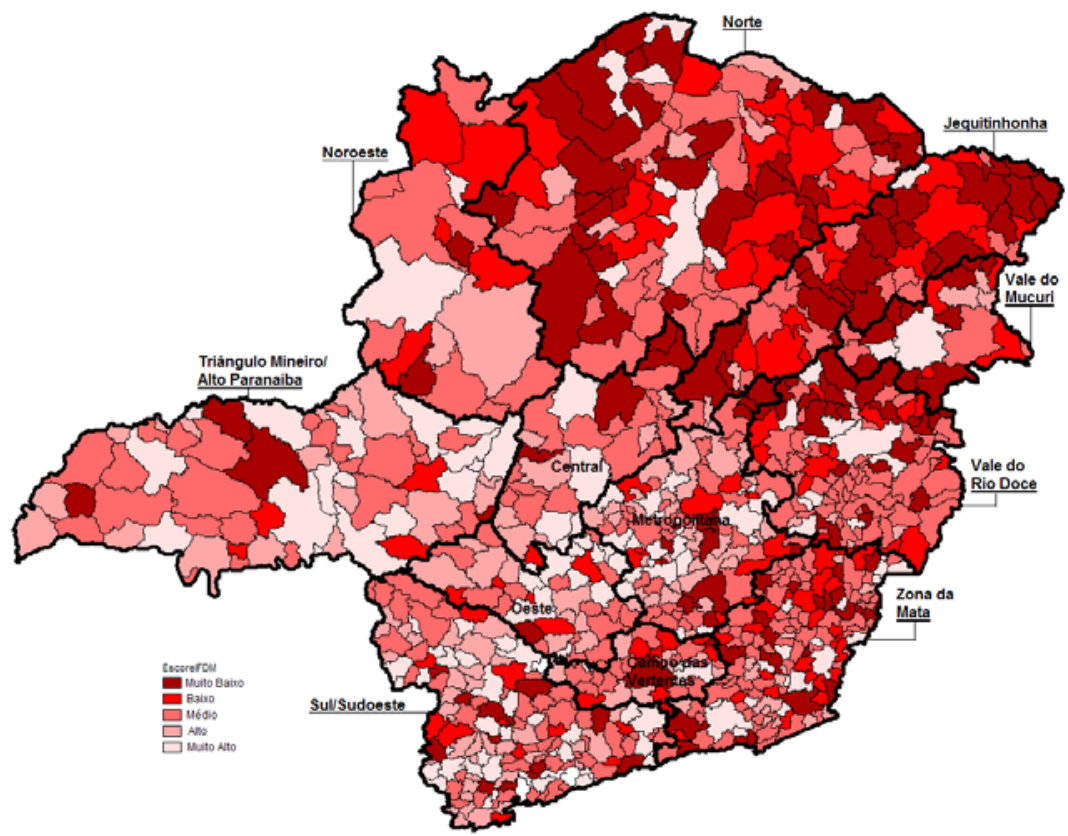

Fonte: Elaborada pelos autores.

Para identificar a interferência dos estratos relacionados ao potencial de arrecadação com o desenvolvimento municipal foi realizada tabulação cruzada (Tabela 4) e teste de Qui-Quadrado (Tabela 5), contemplando os 853 municípios mineiros. Ao apresentar nível de significância abaixo de 1\%, o resultado do teste permite inferir quanto à rejeição da hipótese $\mathrm{H}_{0}$ de que há independência entre as duas variáveis testadas. Constata-se, portanto, que os municípios com maior receita própria per capita geralmente apresentam maiores índices de desenvolvimento socioeconômico. 
Tabela 4 - Tabulação cruzada dos estratos

\begin{tabular}{|c|c|c|c|c|c|c|c|c|}
\hline & & & \multicolumn{6}{|c|}{ Estratos IFDM } \\
\hline & & & $\begin{array}{l}\text { Muito } \\
\text { Baixo }\end{array}$ & Baixo & Médio & Alto & $\begin{array}{l}\text { Muito } \\
\text { Alto }\end{array}$ & Total \\
\hline \multirow{9}{*}{ 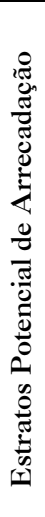 } & Baixo & Observado & 68 & 53 & 125 & 33 & 11 & \multirow{2}{*}{290} \\
\hline & Potencial & Esperado & 47 & 41 & 109 & 51 & 44 & \\
\hline & Potencial & Observado & 65 & 54 & 158 & 75 & 46 & \multirow[b]{2}{*}{398} \\
\hline & $\begin{array}{c}\text { Moderado } \\
\text { Baixo }\end{array}$ & Esperado & 64 & 56 & 149 & 70 & 60 & \\
\hline & Potencial & Observado & 3 & 8 & 17 & 17 & 20 & \multirow[b]{2}{*}{65} \\
\hline & $\begin{array}{c}\text { Moderado } \\
\text { Alto }\end{array}$ & Esperado & 10 & 9 & 24 & 11 & 10 & \\
\hline & Elevado & Observado & 1 & 4 & 20 & 24 & 51 & \multirow{2}{*}{100} \\
\hline & Potencial & Esperado & 16 & 14 & 38 & 18 & 15 & \\
\hline & Total & & 137 & 119 & 320 & 149 & 128 & 853 \\
\hline
\end{tabular}

Fonte: Resultados da Pesquisa.

Tabela 5 - Resultado do teste Qui-Quadrado

\begin{tabular}{lccc}
\hline Teste utilizado & Valor & Graus de Liberdade & Significância \\
\hline Qui-Quadrado de Pearson & 190,173 & 12 & 0,000 \\
\hline
\end{tabular}

Fonte: Resultado da Pesquisa.

Assim, os resultados deste trabalho corroboram o trabalho de Costa et al. (2012), quando constatam que maiores níveis de atividade econômica estão associados a melhores condições socioeconômicas e de finanças públicas, implicando, por consequência, altos níveis de desenvolvimento.

\section{Considerações Finais}

Desde a promulgação da Constituição de 1988, parte significativa dos municípios encontra-se na situação de baixos níveis de arrecadação própria, gerando alta dependência dos recursos provenientes de transferências inter- 
governamentais. Tal fato implica menor fluxo de recursos para cumprimento das obrigações que lhes cabem, tendo por consequência baixo nível de investimentos, comprometendo o desenvolvimento local.

Desse modo, neste trabalho buscou-se identificar a relação entre a composição da arrecadação tributária própria e o nível de transferências intergovernamentais com o desenvolvimento socioeconômico dos municípios mineiros.

Após a estratificação baseada no potencial arrecadatório, definido como a proporção da própria na receita total, os municípios foram caracterizados de acordo com o porte populacional, desenvolvimento municipal, renda, arrecadação própria per capita e configuração do potencial de geração de receitas, por meio do Valor Adicionado Fiscal por setor.

Constatou-se que, pelas medidas de tendência central das variáveis analisadas, os municípios de maior potencial arrecadatório apresentam melhores desempenhos médios das variáveis analisadas, exceto em relação ao VAF per capita das atividades primárias, o que demonstra a ausência de relação entre o potencial arrecadatório e o nível de atividades agropecuárias dos municípios.

Pela caracterização dos estratos, é possível inferir pela associação positiva entre o nível de receitas próprias e a atividade econômica; sinalizando para o efeito positivo da arrecadação dos tributos de competência municipal no índice de desenvolvimento municipal.

Pôde-se concluir pela existência estatisticamente significativa de diferenças entre os estratos quanto à composição da arrecadação tributária, exceto no que se refere à receita per capita do ISS. Dessa forma, comprovou-se que os grupos são distintos em relação aos níveis médios de arrecadação tributária própria, exceto em relação às receitas com ISS, e não têm associação com a classificação dos municípios em todos os estratos de potencial arrecadatório. 
Foi constatado, ainda, que municípios que apresentaram maiores receitas próprias per capita têm maiores índices médios de desenvolvimento socioeconômico, confirmando a expectativa teórica prévia da associação positiva existente entre eles.

Conclui-se, portanto, que, tanto os níveis quanto a composição da arrecadação própria têm associação com o desenvolvimento socioeconômico dos municípios mineiros. Essa associação pode estar relacionada ao fato de que aumentos dos níveis de arrecadação geram aumentos dos níveis de accountability, pois presume-se que o gestor público municipal é responsável pela entrega de serviços públicos de melhor qualidade quando põe em prática meios para aumentar a arrecadação.

Assim, aumentos de arrecadação podem estar relacionados a melhores níveis de desenvolvimento devido à responsabilização atribuída ao gestor público municipal pela melhor gestão dos recursos públicos. Há de se ressaltar a importância da atuação do Estado e dos governos locais em ações para atendimento das demandas criadas pela população e para a promoção do desenvolvimento socioeconômico, o que implicaria o aumento do nível de arrecadação.

Este texto apresenta como principal limitação o fato de se ter utilizado predominantemente de variáveis econômicas, considerando que o desenvolvimento municipal é fruto de um conjunto de variáveis relacionadas à saúde, educação, infraestrutura e potencial econômico. Além disso, a abordagem em seção cruzada permitiu apenas constatações da associação entre as variáveis, não sendo possível responder quanto à simultaneidade dos seus efeitos.

Apesar dessas limitações, a relevância desta pesquisa reside no fato de explorar conjuntamente variáveis relacionadas à estrutura arrecadatória, capacidade econômica e potencial de arrecadação vinculada ao desenvolvimento socioeconômico, permitindo assim estabelecer estudos relacionados a políticas fiscais, gestão e controle e ações diferenciadas em relação aos estratos de municípios formados. Assim, para estudos futuros, sugere-se 
a análise dos efeitos da composição da arrecadação tributária no desenvolvimento socioeconômico em perspectiva temporal, a fim de responder o problema da endogeneidade entre essas variáveis.

\section{Referências}

AFFONSO, R. A crise da Federação no Brasil. Ensaios FEE, v. 15, n. 2, p. 321-337, 1994.

AFONSO, J. R. R. Descentralização fiscal, políticas sociais e transferência de renda no Brasil. Santiago do Chile, CEPAL. 2007. (Serie Gestión Pública, n. 63).

AGUIAR, N. Finanças locais e recursos naturais em regiões periféricas. Proceedings do IX Workshop APDR, descentralização financeira e desorçamentação. Braga: Universidade do Minho, 2011.

ARRETCHE, M. Federalismo e políticas sociais no Brasil: problemas de coordenação e autonomia. São Paulo em Perspectiva, v. 18, n. 2, p. 17-26, 2004.

BAIÃO, A. L. O papel das transferências intergovernamentais na equalização fiscal dos municípios brasileiros. 2013. Dissertação (Mestrado em Administração) - Escola Brasileira de Administração Pública e de Empresas, Rio de Janeiro, 2013.

BARACHO, M. A. P. A importância da gestão de contas públicas municipais sob as premissas da governance e accountability. Revista Tribunal de Contas de Minas Gerais, Belo Horizonte, v. 34, n. 1, p. 129-161, 2000.

BRASIL. Constituição da República Federativa do Brasil: promulgada em 5 de outubro de 1988. Disponível em: <http://www.planalto.gov.br/ccivil_03/constituicao/constituicao.htm>. Acesso em: 3 set. 2014.

. Lei Complementar 101, de 4 de maio de 2000. Dispõe sobre responsabilidade na gestão fiscal e dá outras providências. Disponível em: <http://www2.camara.leg.br/ legin/fed/leicom/2000/leicomplementar-101-4-maio-2000-351480-normaatualizada-pl.html>. Acesso em: 3 set. 2014.

BRUNI, A. L. SPSS aplicado à pesquisa acadêmica. São Paulo: Atlas, 2009.

COSTA, C. C. M. et al. Fatores associados às transferências voluntárias da união para os Estados brasileiros. Encontro Nacional da Anpad-Enanpad, v. 35, 2011. 
COSTA, C. C. M. et al. Disparidades inter-regionais e características dos municípios de Minas Gerais. Desenvolvimento em Questão, ano 10, n. 20, p. 52-88, 2012.

DELGADO, V. M. S., MACHADO, A. F. Eficiência das escolas públicas estaduais de Minas Gerais. Pesquisa e Planejamento Econômico, v. 37, n. 3, p. 427-464, 2007.

EZCURRA, R.; PASCUAL, P. Fiscal Decentralization and Regional Disparities: evidence from several European Union Countries. Environment and Planning. v. 5, n. 40 , p. 1.185-1.201, 2008.

GANDINI, R. Características patrimonialistas do Estado brasileiro: anotações para estudos de política educacional. Revista Brasileira de Política e Administração da Educação, v. 24, n. 2, p. 197-213, 2008.

GIAMBIAGI, F. ALÉM, A. C. D. Finanças públicas. 2. ed. Rio de Janeiro: Elsevier, 2000.

HAIR, J. F. et al. Análise multivariada de dados. 5. ed. Porto Alegre: Bookman, 2009. KAPPELER, A.; VÄLILÄ, T. Fiscal federalism and the composition of public investment in Europe. European Journal of Political Economy, v. 24, n. 3, p. 562-570, 2008.

KERBAUY, M. T. M. Federalismo, descentralização e democracia. Estudos de Sociologia, v. 6, n. 10, p. 51-61, 2001.

LIMA, A. C. C.; SIMÕES, R. F. Teorias do desenvolvimento regional e suas implicações de política econômica no pós-guerra: o caso do Brasil. Texto para Discussões, n. 358, 2009.

MASSARDI, W. O. Esforço fiscal e desempenho socioeconômico dos municípios mineiros. Viçosa/MG. 2014. Dissertação (Mestrado em Administração) - Universidade Federal de Viçosa, 2014.

MATIAS-PEREIRA, J. Finanças Públicas: A Política Orçamentária no Brasil. $4^{\mathrm{a}}$ edição. São Paulo: Editora Atlas, 2009.

MEDEIROS, C. A. Desenvolvimento econômico, heterogeneidade estrutural e distribuição de renda no Brasil. In: Conferência Internacional da Rede de Estudos sobre o Desenvolvimento Celso Furtado: repensar a teoria do desenvolvimento num contexto de globalização, 3. Rio de Janeiro: IE, 2004.

MUSGRAVE, R. Teoria das finanças públicas. São Paulo: Atlas, 1974.

MUSGRAVE, R.; MUSGRAVE, P. Finanças públicas: teoria e prática. São Paulo: Campus/USP, 1980. 
MYRDAL, C. Teoria econômica e regiões subdesenvolvidas. Rio de Janeiro: Saga, 1968.

NAZARETH, P. A. C. P. Descentralização e federalismo fiscal: um estudo de caso dos municípios do Rio de Janeiro. 2007. Tese (Doutorado em Economia) - Universidade Federal do Rio de Janeiro, Rio de Janeiro, 2007.

OATES, W. E. Toward a Second-Generation Theory of Fiscal Federalism. International Tax and Public Finance, 2005.

OLIVEIRA, F. A. de; BIONDINI, I. V. F. IDTE: um índice de finanças para a análise do desenvolvimento: o caso dos municípios de Minas Gerais. In: XV SEMINÁRIO SOBRE A ECONOMIA MINEIRA, 15., 2012, Diamantina. Anais... Diamantina: Universidade Federal de Minas Gerais, 2012.

OLIVEIRA, J. C. Análise do crescimento econômico e das desigualdades regionais no Brasil. Estudos do Cepe, Santa Cruz do Sul, n. 28, p. 5-28, jul./dez. 2008.

ORAIR, R. O.; ALENCAR, A. A. Esforço fiscal dos municípios: indicadores de condicionalidades para o sistema de transferências intergovernamentais. Monografia premiada do Tesouro Nacional. Brasília, 2010.

REGAZZI, Adair José. Curso de iniciação à estatística. Universidade Federal de Viçosa: Viçosa, 2007.

REZENDE, F. Finanças públicas. São Paulo: Ed. Atlas, 2001.

SAMPIERI, R. H.; COLlADO, C. F.; LUCIO, P. B. Metodologia de pesquisa. 3. ed. São Paulo: McGraw-Hill, 2006.

SANTOS, T. C. Descentralização e a distribuição do poder no território: o papel do Estado e a legislação federal. 2002. Disponível em: <www.uff.br/lacta/.../descentralizacaoedistribuicaodopoder.doc>. Acesso em: 12 dez. 2011.

SEGRETARIA DO TESOURO NACIONAL (STN). Contas anuais. Disponível em: <http://www.tesouro.fazenda.gov.br/contas-anuais>. Acesso em: $1^{\circ}$ set. 2014.

SEPULVEDA, C. F; MARTINEZ-VAZQUEZ, J. The Consequences of Fiscal Decentralization on Poverty and Income Equality. Environment and Planning $C$ : Government and Policy, v. 2, n. 29, p. 321-343, 2011.

SERRA, J.; AFONSO, J. R. R. Federalismo fiscal à brasileira: algumas reflexões. Revista do BNDES, Rio de Janeiro, v. 6, n. 12, p. 3-30, 1999.

SHIKIDA, C. D. A economia política da emancipação de municípios em Minas Gerais. Brasília: Esaf, 1998. 
SIEDENBERG, D. R. Indicadores de desenvolvimento socioeconômico: uma síntese. Desenvolvimento em Questão, v. 1, n. 1, p. 45-71, 2003.

SILVA, V. M. Os municípios paulistas e o federalismo fiscal brasileiro. São Paulo: Imesp; Cepam, 1995.

SIQUEIRA, K. J. S. P. Esforço fiscal dos municípios pernambucanos: uma análise de fronteira estocástica. 2014. Dissertação (Mestrado em Economia) - Universidade Federal de Pernambuco, Recife, PE, 2014.

SOUZA, C. Intermediação de interesses regionais no Brasil: o impacto do federalismo e da descentralização. Dados, v. 41, n. 3, 1998.

SOUZA, C. O. Esforço fiscal e alocação de recursos nos municípios da Zona da Mata de Minas Gerais. 2007. Dissertação (Mestrado em Administração) - Universidade Federal de Viçosa, Viçosa/MG, 2007.

TAMEZ, C. A. S.; MORAES JUNIOR, J. J. Finanças Públicas. Rio de Janeiro: Elsevier, 2007.

TRIOLA, M. F. Introdução à estatística. 10. ed. Rio de Janeiro: LTC, 2008.

WEINGAST, B. R. Second generation fiscal federalism: The implications of fiscal incentives. Journal of Urban Economics, v. 65, n. 3, p. 279-293, 2009. 